The inhibitory factor was slightly soluble in water and more soluble in alkali, as was the colouring matter produced by exposure to light.

The chemical nature of the inhibiting factor is undes investigation. It is possible that it is an 0 -hydro quinone; it does not appear to be an oxidatior product in which meso-carbon atoms are involved. Comparison with reduced $\beta$-naphthaquinone and a reduced $1: 2: 5: 6$-dibenz-3:4-anthraquinone ${ }^{2}$ showed the activity to be similar to that developed by the compounds named in the table above. The active compound derived from $1: 2: 5: 6$-dibenzanthracene is therefore possibly

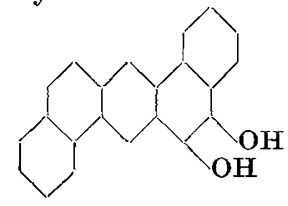

Such a compound would have the structure $-\mathrm{C}_{-}^{\mathrm{O}_{-}^{\mathrm{H}}}-\mathrm{C}^{\mathrm{O}_{-}^{\mathrm{H}}}$ which is similar to one of the groupings considered by Quastel and Wooldridge ${ }^{3}$ to be necessary for the inhibition of lactic dehydrogenase. Full details of these experiments will be published shortly.

Research Institute,

E. BOYLAND.

The Cancer Hospital (Free), London,

$$
\text { July } 28 .
$$

1 The Production of Cancer by Pure Hydrocarbons, (Pt. 1) by J. W, 1 The Production of Cancer by Pure Hydrocarbons, (Pt. 1) by J. W,
Cook, I. Hieger, E. I. Kennaway, and W. V. Mayneord, (Pt. 2) by J. W. Cook, Proc. Roy. Soc., B (in the press).

J. W. Cook. Unpublished results.

3 Biochem. J., 22, 689; 1028.

\section{Isolation of Chemically Unstable Substances from Animal Tissues}

In the course of a study of some chemically unstable constituents of muscle tissue, we have made successful use of the following method for obtaining protein-free extracts of muscle. It has the merit of yielding, without departure from neutrality, a proteinfree solution of the water-soluble constituents of musele in a concentrated form. We have been unable to find a description of this technique in the literature, but should be grateful for information as to earlier examples of its use.

The method is based upon the facts that at $32^{\circ} \mathrm{C}$. the solubility of sodium sulphate in water is at its maximum $-50 \mathrm{gm}$. of the anhydrous salt to $100 \mathrm{gm}$. of water-and that if such a solution is cooled to $0^{\circ}$ C., 96 per cent of the salt crystallises out as the decahydrate.

If muscle tissue, which contains water to the extent of 80 per cent of its weight, is minced with 40 per cent of its weight of anhydrous sodium sulphate, about three-quarters of the water of the muscle can be expressed without difficulty in the form of a saturated solution of sodium sulphate at $32^{\circ} \mathrm{C}$. The solution contains no protein. The mother liquor poured away from this solution after chilling would be expected, on the basis of the figures given above, to contain the water-soluble constituents of the muscle in a concentration about three times greater than in the muscle. The following table, taken from a typical experiment, shows that this is the case.

The yield, unless special precautions are taken, is not very good-50-60 per cent-but in view of the ease and rapidity of the process and the high concentration of the extract, this is, for most purposes, not a serious drawback.

We have applied this technique so far only to the isolation of creatine, which can be precipitated im- mediately from the extract by addition of acetone, and of carnosine and anserine, which can be prepared from the extract by the use of copper carbonate,

\begin{tabular}{|c|c|c|c|}
\hline & $\begin{array}{c}\text { Concentra- } \\
\text { tion in } \\
\text { Muscle. } \\
\text { Mgm. per } \\
100 \mathrm{gm} \text {. }\end{array}$ & $\begin{array}{c}\text { Concentra- } \\
\text { tion in } \\
\mathrm{Na}_{2} \mathrm{SO}_{4} \\
\text { Extract. } \\
\text { Mgin. per } \\
100 \mathrm{gm} \text {. }\end{array}$ & $\begin{array}{l}\text { Concentra- } \\
\text { tion ratio. }\end{array}$ \\
\hline $\begin{array}{l}\text { Carnosine } \\
\text { (by Pauli reaction) }\end{array}$ & 35 & 112 & $3 \cdot 2$ \\
\hline Non-protein nitrogen & 247 & 690 & $2 \cdot 8$ \\
\hline Lactate & 250 & 700 & $2 \cdot 8$ \\
\hline Total phosphorus & 118 & 303 & $2 \cdot 6$ \\
\hline
\end{tabular}

acetone, and ammonia. The yield of crystalline copper carnosine or copper anserine compares favourably with the yields recorded by investigators using more elaborate methods. We have obtained in this way anserine from the muscles of sheep, goat, and rabbit, and carnosine from ox and frog muscle.

M. G. EgGLETON.

Physiology Department, P. Eggleton.

University, Edinburgh, July 20.

Observations on Filmed and Filtered Vowels

Some specimens of film curves of German vowels obtained by the Vienna method of recording (wire in magnetic field slantways across a slit ${ }^{1}$ ) are reproduced in Fig. 1. Inspection of the curves reveals the following facts: (1) A vowel is made up of a series of adjacent vibration profiles; (2) the profiles differ progressively in length, amplitude, and form; (3) each
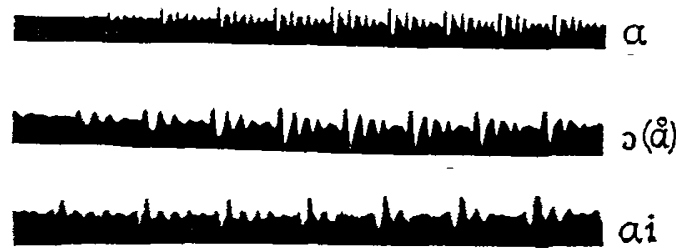

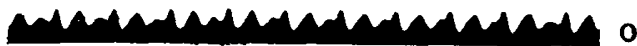
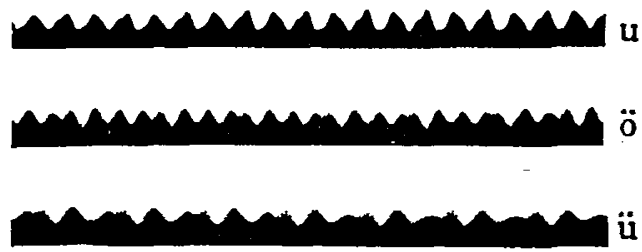

Fio. 1.-Film curves of vowels.

profile begins strong and becomes steadily weaker; (4) within each profile various characteristies, for example, maxima, are repeated; (5) different vowels show systematic differences of profile. Measurements reveal the following additional facts: (6) the frequencies of the inner repetitions change within each profile; (7) the rate of weakening changes within each profile.

These facts lead to the following conclusions: (1) The vibration profile is initiated by a sharp impulse that does not appear in the curve of the profile; (2) the profile consists of a more or less rapidly fading free vibration of complicated form.

The numerous systems of inner repetition suggest that the free vibration constituting the profile might

No. 3277 , Vou. 130] 